\title{
LA RETÓRICA EN EL GORGIAS DE PLATÓN Y SU TEORÍA POLÍTICA EN EL PRESENTE: POSMODERNISMO Y POPULISMO
}

\section{RHETORIC IN PLATO'S GORGIAS AND HIS POLITICAL THEORY IN THE PRESENT: POSTMODERNISM AND POPULISM}

\author{
Francisco de Sales Sánchez Andrada ${ }^{1}$ \\ Universidad Autónoma de Madrid \\ Campus de Cantoblanco, Calle Francisco Tomás y Valiente, 1, 28049 Madrid, \\ España \\ franciscos.sanchez@estudiante.uam.es
}

\begin{abstract}
RESUMeN
Siguiendo la tesis en virtud de la cual el Gorgias versa sobre la cuestión de la retórica, en el presente artículo se aborda la definición de esta idea a fin de establecer las diferencias entre el orador y el filósofo. No en vano, aunque retórica se define como una práctica y no como un arte (tekhnai), Platón no niega que el filósofo pueda acudir a ella para alcanzar el bien del alma de la polis. Pero, entonces, ¿quién es el gobernante ideal que garantice el bien de los ciudadanos de Atenas? Trataremos de responder a esta pregunta analizando esta figura platónica, representada en la persona de Sócrates. Así, cuando Platón responde al interrogante
\end{abstract}

Máster en Filosofía de la Historia: Orden Mundial y Democracia. 
sobre quién debe gobernar la ciudad está construyendo su teoría política. Para finalizar, analizamos la analogía entre esta teoría política y dos de las ideologías predominantes en la actualidad: el posmodernismo y el populismo.

Palabras clave: retórica, filósofo, orador, posmodernismo, populismo.

\begin{abstract}
Following the thesis and considering that Gorgias is about rhetoric, this paper deals with the definition of this idea so it can establish the differences between the orator and the philosopher. In fact, although rhetoric is defined as an ability and not as a technique, Plato does not deny that the philosopher can use it to achieve the Good of the soul of the polis. But, then, who is this ideal governor who assures the good of the citizens of Athens? We will try to answer this question analyzing this platonic figure, represented in Socrates. In this way, when Plato answer to the question about who should govern the polis, he is building his political theory. To finish, we will analyze the analogy between this political theory and two of the most main ideologies nowadays: postmodernism and populism.
\end{abstract}

Keywords: Rhetoric, Philosopher, Orator, Postmodernism, Populism. 


\section{INTRODUCCIÓN}

El Gorgias ${ }^{2}$ supone uno de los diálogos platónicos más importantes sobre la cuestión de los sofistas en la Atenas de aquel tiempo. En este texto, Platón esboza aquello que con mayor concreción aborda en la República, a saber, el alma de la polis, las ideas de moral y justicia y la cuestión de quién debe gobernar la ciudad, lo que Olimpiodoro resumió afirmando que el argumento del Gorgias era la discusión sobre los principios morales que conducen al bienestar político. En la base de estas dos ideas se encuentra el interés de Platón por definir el concepto de retórica y presentar la figura del orador (rhetor) en contraposición a la del filósofo (philosophos).

La obra se compone de tres diálogos en los que Sócrates se enfrenta a tres sofistas. Su estructura es particular, en tanto que estos se desarrollan sucesivamente sin que los personajes que no son protagonistas de cada parte intervengan en ella. En primer lugar, Sócrates conversa con Gorgias de Leontinos, el sofista más adinerado de la época y, en palabras de Filóstrato, el padre de la sofística. Tras Gorgias, interviene Polo, sobre quien se afirma que era el joven discípulo de Gorgias. En último lugar, el diálogo se mantiene con Calicles, de cuya existencia real se duda ${ }^{3}$.

Como hemos afirmado, este diálogo se ha entendido, ya desde la antigüedad, como una obra que versa sobre la retórica, cuestión a analizar en el presente artículo junto con la adaptación al presente de la teoría política que reluce del Gorgias. Así, el primer punto aborda la definición de retórica y las diferencias entre el orador y el filósofo. El segundo, plantea una pregunta clásica sobre la obra de Platón, esto es, saber si la retórica es necesaria y abordar la consideración sobre si Sócrates hacía uso de ella. A continuación, se examina la gran cuestión platónica de quién debe gobernar

2 La edición utilizada para el presente artículo es la del Consejo Superior de Investigaciones Científicas de Madrid (2000), edición crítica, traducción, introducción y notas por Ramón Serrano Cantarín y Mercedes de Díaz de Cerio Díez.

3 Guthrie y Dodds lo consideran un personaje histórico que, por sus ideas radicales y ambición desmedida, pudo morir prematuramente en los ańos finales de la guerra del Peloponeso. Para Menzel no hay duda de que se trata de una personificación del tirano Critias. 
la polis. Para finalizar, y habida cuenta de la tendencia histórica a adaptar la teoría política de Platón al presente, se presentan las similitudes entre dos de las grandes corrientes ideológicas del presente, las ideologías posmodernas y el populismo, y lo analizado por Sócrates y sus contertulios en el Gorgias.

\section{2. ¿QUÉ es LA Retórica? El orador y el FILÓSOFO}

Antes de abordar el concepto de retórica, resulta necesario vertebrar un breve análisis de la figura del sofista en virtud de su relación con los protagonistas del Gorgias. Etimológicamente, la palabra sofista proviene del prefijo griego sophos, que significa sabio, y del sufijo istes, del mismo origen y cuyo significado hace referencia al carácter de lo expuesto; luego, el sofista sería el profesional del saber. El primer significado más preciso de sofista lo encontramos en Eurípides en el siglo VIII a. C., quien lo utilizó para caracterizar a los siete sabios de Grecia. Sin embargo, como afirma José Solana, no es hasta el siglo $\mathrm{V}$ a. C. cuando este término pasó a tener una definición más restringida (89). Hasta entonces, se aplicaba a poetas o músicos y, de forma general, a todo aquel que tuviera que ver con la educación. A partir de ahí, entran en juego dos variables: la profesionalidad y la política como ámbito principal sobre el que teorizar. Es en este contexto, el de su profesionalización, donde se materializa la sustitución de los poetas por los sofistas en la paideia.

Pueden encontrarse múltiples definiciones de sofista por parte de Platón. Las más destacadas para el tema que aquí tratamos las encontramos en el Protágoras, como mayorista o traficante de las mercancías del alma (Protágoras 313c), y en el Sofista, como pescador de caña (Sofista 224c). Por lo tanto, el sofista es el profesional de la enseńanza; es decir, aquel que cobra un salario por impartir diferentes contenidos, siendo el paradigma de su técnica la retórica. Sin embargo, y como veremos a continuación, Platón expone la retórica en el Gorgias como lo practicado por una figura diferente al sofista, no siendo además aquella un arte (tekhnai) en sí. Ateniéndonos a la obra que analizamos, en la misma se encuentran dos definiciones de retórica: la de Gorgias y la de Sócrates. 
Aunque la visión de la retórica de los sofistas cristalice en el diálogo mantenido con Gorgias, es Polo quien, en primer lugar, tiene relevancia a estos efectos cuando, ante el exhorto de Querofonte -quinto personaje en la obra ${ }^{4}$ - por nombrar el arte del que es conocedor Gorgias, responde que conoce de la más hermosa de las artes (Platón, Gorgias 448c). Esta réplica resulta de interés por ser la primera vez en la obra en la que Sócrates critica el método retórico en contraposición al método dialéctico (elenkhos) al afirmar lo siguiente: "al preguntarte Querefonte en qué arte es Gorgias experto, la alabas como si alguien la criticara, pero no has respondido cuál es" (Platón, Gorgias 448d). Ante la indefinición de Polo, Sócrates dialoga con Gorgias a fin de encontrar una definición de retórica. La conclusión para Gorgias es que la retórica es ser capaz de persuadir por la palabra a los jueces en los tribunales, a los consejeros, en el consejo; a los asambleístas, en la asamblea y en cualquiera otra reunión que haga referencia a los asuntos de la ciudad (Platón, Gorgias 452e).

La respuesta de Sócrates formaliza la primera gran cuestión del Gorgias: la diferencia entre arte (tekhnai) y práctica junto al concepto de adulación. El esquema socrático es el siguiente: el hombre está compuesto de cuerpo y alma, cada una de estas tiene un arte particular. En el caso del alma, la política y en el caso del cuerpo, queda dividido entre la gimnasia y la medicina. A su vez, la política se fragmenta en dos partes, la legislación y la justicia. Estas artes tienen como fin cuidar del alma y del cuerpo respectivamente. Por otro lado, cada una de las cuatro tiene su contraposición, en el caso de la gimnasia se trata de la cosmética; para la medicina, la cocina; para la legislación, la sofística y para la justicia, la retórica. Estos conceptos contrapuestos no tienen como fin la búsqueda del bien, sino que, fingiendo ser las artes que componen cuerpo y alma y sirviéndose del placer, producen engaño hasta el punto de parecer dignas de tener la apariencia de ser de inmenso valor. Su fin es encontrar el placer sin el bien, siendo todas ellas partes

Los cinco personajes que dialogan en el Gorgias son Sócrates, Gorgias, Querofonte, Polo y Calicles. 
de la adulación. Por lo tanto, si la cocina, la cosmética, la sofística y la retórica no buscan el bien, no pueden ser artes, sino otra cosa; esto es, práctica (Platón, Gorgias 463b-466a).

Así, Platón plantea la diferencia entre la búsqueda del placer y la búsqueda del bien de cuya dicotomía saldrán dos paradigmas antitéticos: el filósofo (philosophos) y el orador (rhetor) 5 . Estas dos instituciones tienen métodos diferentes, mientras que el filósofo utiliza la dialéctica, el orador utiliza la retórica. No obstante, el método utilizado no es la única característica no compartida. Como puede observarse en diversos pasajes del Gorgias, las discrepancias entre estas dos figuras pueden ser de forma y de fondo.

En cuanto a las diferencias de forma, en el diálogo encontramos múltiples fragmentos en los que se constatan los desacuerdos entre el filósofo y el orador. Por ejemplo, en el contexto de la discusión central de la obra, saber si es preferible recibir a cometer injusticia, Polo ironiza en referencia a la felicidad de Arquelao, rey de Macedonia e hijo de una esclava, afirmando que "empezando por ti, hay quizás algún ateniense que preferiría ser cualquier macedonio antes que Arquelao" (Platón, Gorgias 471e-471d). La respuesta de Sócrates sirve como muestra de las discrepancias existentes en las formas entre este y el resto de sofistas: "Ya al empezar la conversación, Polo, te felicité porque me parece que tienes una buena formación para la retórica, pero que te has despreocupado de la práctica del diálogo. Pues bien, ahora, ¿es este el razonamiento con el cual hasta un niño podría demostrar que estoy equivocado?" (Platón, Gorgias 471d). También son destacables, como ejemplo de lo aquí analizado, las múltiples ocasiones en las que Sócrates exige a su interlocutor que no se exceda en la duración de sus discursos y que siga el método referido (Platón, Gorgias 449b): el de pregunta y respuestas cortas. La misma petición la encontramos en diversos diálogos platónicos.

Para los griegos, originalmente la palabra retos se refiere a lo que se ha dicho, lo que ha sido estipulado, acordado o convenido, o que es decible, expresable en palabras. De ahí que rhetor designe por igual a aquel que dice y se expresa con palabras, o sea el orador, y al que usa las palabras para estipular, convenir o acordar cosas, es decir, el político. 
Pero las diferencias también pueden analizarse desde la perspectiva de los sofistas. Como afirma Antonio Melero, uno de sus rasgos distintivos es el uso del arte de la erística (tekhne eristikon), cuya finalidad es la búsqueda de la victoria en el debate por cualquier medio y con independencia de la verdad (28). El objetivo es vencer en la argumentación por encima de todo. Así, podemos citar como ejemplo de uso erístico la falacia que Polo utiliza en la disputa dialéctica sobre Arquelao cuando le manifiesta a Sócrates, tras su argumentación, lo siguiente: "Porque no quieres, que tú opinas lo mismo que yo" (Platón, Gorgias 471e). En ese mismo contexto, y tras afirmar Sócrates que es más desgraciado el que escapa al castigo y consigue ser tirano que quien es castigado, vemos otro uso erístico cuando Polo se ríe del argumento de Sócrates (Platón, Gorgias 473e). La erística conformaba una característica de un tipo concreto de retórica basada en saber insultar o adular sin contenido alguno: la retórica epidíctica.

En realidad, el fundamento por el cual no puede confundirse el método retórico sofístico con el método filosófico es que el primero se articula en virtud de las imágenes que son propias del ámbito de la doxa y el segundo proviene de un saber constituido en el nous. De ahí la diferencia que posteriormente es analizada entre el filósofo (de sophos, saber) y el filodoxo (de doxa, opinión). Todas estas diferencias de forma esconden el verdadero motivo del enfrentamiento entre el orador y el filósofo, entre Platón y los sofistas; a saber, que ambos se consideraban rivales filosóficos y que concretamente Platón desplegó contra ellos una intensa actividad refutatoria por tal razón. Como Gustavo Bueno afirmaba: "pensar es siempre pensar contra alguien", es decir, pensar contra los sofistas y, concretamente, contra Protágoras. Entre los enfrentamientos conceptuales del platonismo y la sofística se encuentra la diferente percepción de nomos (ley o convención) y physis (naturaleza). Es Guthrie quien defiende que la creencia en la antítesis entre nomos y physis constituye un elemento común al pensamiento genérico de los sofistas y un papel fundamental en la teoría política de estos (57). Como afirma Castoriadis, "a la naturaleza (physis) infrangible e inmutable aun en sus cambios, se oponen las leyes de las comunidades humanas (nomoi), contingentes, convencionales, arbitrarias" 
(332). En el Gorgias esto se ve reflejado en la posición de Calicles, quien defiende la superioridad de la physis y el conflicto de esta con el nomos a fuer de la defensa del tirano, una perspectiva que recuerda a la que tiene Trasímaco en el Libro I de la República.

\section{3. ¿Consideraba Platón necesaria la retórica?}

Para responder a esta pregunta hay que comenzar por analizar el concepto de persuasión (peitho), reiterado en diversos pasajes del Gorgias. Dentro de la definición de retórica anteriormente examinada, encontramos como un elemento fundamental esta noción. De esta manera, tras manifestar Gorgias que la retórica se encarga del mayor bien, a saber, ser capaz de persuadir en toda reunión sobre asuntos públicos, Sócrates responde que, entonces y, según su razonamiento, la retórica es "artífice de persuasión" (Platón, Gorgias 453a.). Sin embargo, Sócrates no está de acuerdo con esta definición puesto que la capacidad de persuadir también está incluida en otras artes; así, la aritmética convence sobre todo en relación con los números; luego cada arte requiere de un tipo concreto de persuasión y un objeto sobre el que se dirija (Platón, Gorgias 453b-453e). Por lo tanto, el concepto de persuasión es necesario para la definición de retórica, pero no suficiente para dar razón de su esencia.

Habida cuenta de que la persuasión se encuentra en todas las artes, Sócrates organiza una taxonomía sobre los tipos de persuasión, aquella que proporciona ciencia (episteme) y aquella que proporciona creencia sin conocimiento (Platón, Gorgias 454e), donde se encontraría la retórica. Como indica Silvia Tonti, Platón plantea una nueva división dicotómica en tanto que divide el género -persuasión- en sus respectivas especies -la que produce creencia y la que produce ciencia- (121). Por esta razón, no puede considerarse a la persuasión como exclusiva de la retórica, sino que es un elemento ansiado tanto en esta como en la filosofía. En palabras de José Antonio Sánchez Tarifa, la persuasión retórica y la dialéctica distan mucho entre sí. La retórica produce un convencimiento momentáneo, casi 
siempre debido a argumentos superficiales de fácil acogida en los auditorios. El persuadido por la retórica, como le sucede a Polo en el Gorgias o a Fedro en el Fedro, apenas sabe explicar el porqué de sus convicciones, dejándose arrastrar por una exaltación efímera del poder de la palabra (311).

Esta definición de persuasión resulta clave para responder a la pregunta planteada, esto es, ¿consideraba Platón necesaria la retórica? O lo que es lo mismo, ¿̨puede el filósofo gobernar la polis sin usarla? La relación existente entre la retórica y la política es palpable cuando Sócrates, tras articular el esquema que separa las artes de las prácticas, comienza a ejemplificar diferentes actividades cuyo fin es agradar a las almas sin preocuparse de lo que es mejor para ellas; es decir, aquellas que son adulación. Así, Sócrates argumenta que la oratoria poética, que es poesía desprendida de melodía, ritmo y medida, no es sino una forma de oratoria popular que se dirige a niños, mujeres, hombres libres y esclavos. A continuación, le dirige a Polo el siguiente exhorto:

Muy bien. ¿Y la retórica que se ejerce ante el pueblo ateniense y ante los pueblos de las ciudades de hombres libres? ¿Qué decimos que es? ¿Te parece que los oradores hablan siempre mirando a lo que es mejor, apuntando a que los ciudadanos alcancen el grado máximo de perfección posible gracias a sus discursos? ¿ $\mathrm{O}$ que también ellos se mueven tratando de agradar a los ciudadanos, y que, en aras del propio bien particular despreciando el bien común, tratan al pueblo como a un niño, tratando únicamente de agradarles, sin preocuparse en absoluto de si por ello se harán mejores o peores? (Platón, Gorgias 502e)

Sócrates introduce el debate en este momento, que consistente en saber si los oradores pueden tener como intención la búsqueda del bien de los ciudadanos o solo tienen como fin agradar. La respuesta de Gorgias es que algunos dicen lo que dicen preocupándose de los ciudadanos y otros como dice Sócrates. Teniendo en cuenta cómo definimos anteriormente retórica, la respuesta sobre la pregunta de si puede existir otro tipo de retórica que busque el bien para el alma de la polis, la encontramos en el soliloquio de Sócrates situado en la parte, cuando manifiesta que "hay que evitar toda 
adulación, tanto de uno mismo, como de los demás, de los pocos y los muchos; y la retórica -y toda otra actividad- ha de ser empleada siempre para la justicia” (Platón, Gorgias 527c).

En conclusión, Platón considera en el Gorgias que la retórica utilizada por los oradores, que son políticos, no tiene nada de bello porque busca el placer sin el bien; sin embargo, ello no es óbice para que se puede utilizar otro tipo de retórica, obligadamente necesaria a la hora de hacer política. Luego, si Platón consideraba que la retórica era necesaria para la política $y$, en consecuencia, era utilizada para ello, se abre otro interrogante, a saber, ¿qué tipo de retórica practicaba Sócrates? No en vano, son varias las ocasiones en las que Calicles lo acusa de comportarse como un auténtico orador demagógico y popular, por manipular y usar en su beneficio los conceptos de naturaleza y convención (Platón, Gorgias 483a) y por hacer reducciones a lo absurdo al afirmar que si feliz es quien satisface sus deseos, lo es quien tiene picores y se rasca (Platón, Gorgias 494d).

En realidad, y a pesar de que tal como lo señalamos en el segundo punto, la filosofía de Platón se articula dialécticamente contra los sofistas, no es extraño encontrar similitudes entre ambos, puesto que, además de que la persuasión y la retórica son necesarias en política y política era lo que hacía Sócrates, no hay que olvidar que Platón admira a los sofistas a la vez que se enfrenta a ellos. No en vano, como expresa Gustavo Bueno en su análisis del Protágoras, Platón no acabó con los sofistas de igual manera que la medicina no puede acabar con las enfermedades, tan solo es posible mantenerlos a raya, pero siempre habrá sofistas porque tanto la multitud como el gobierno necesitan esta figura (33).

\section{El buen gobernante platónico del Gorgias}

Que no pueda negarse la función del sofista no quiere decir que Platón creyera que ellos debían gobernar. Como analizaría en la República a través de la figura de los gobernantes, primera clase del alma de la polis, quienes eran los excelentes (aristois) administradores de la polis. Pero los aristois 
deben conocer, porque sin conocimiento no hay excelencia (arete); luego, para gobernar hay que conocer (de episteme) y la razón de esto es impedir que los ignorantes gobiernen. En términos platónicos, los ignorantes son los que buscan lo mejor para sí; esto es, los tiranos.

En el Gorgias, Sócrates, debatiendo con Calicles sobre si es virtud saciar las propias pasiones y las de los demás, acude a la idea de orden (kosmos) para examinar las características de un buen gobernante. Así, si los pintores, arquitectos y armadores un cierto orden en sus obras, obligando a que cada cosa sea conveniente y armónica con otra hasta que el todo queda dispuesto como un objeto sistemáticamente organizado, es porque el orden es bueno y todo aquello que no lo tenga es malo; por lo que, para tener un cuerpo y un alma en buen estado, se requiere que haya conveniencia y armonía. Si el cuerpo que resulta del orden y la armonía es saludable, al buen orden y a la armonía del alma se le da el nombre de norma y ley, de donde los hombres se hacen justos y ordenados; lo que es justicia (dikaiosyne) y moderación (sophrosine). Por esta razón, el buen gobernante será el que sea honrado y se ajuste a estas virtudes, dirigiendo el alma de los ciudadanos hacia el bien (Platón, Gorgias 503e-504e).

Por lo tanto, este buen gobernante que traza Platón en el Gorgias tiene como fin mejorar el alma de los ciudadanos de la polis; para ello ha de tener conocimiento y no creencia, porque si no lo tiene, no hay excelencia (arete). Así, la política platónica será la aplicación de la filosofía a la práctica. Como también trató en la República, el político tiene que ser un filósofo y no un filodoxo (Platón, República 475d). Además, entre estas dos figuras, el buen gobernante, a fin de persuadir al individuo para lograr el bien común, podrá utilizar como medio la noble mentira (gennaion pseudos); luego las mentiras de los filósofos que han de gobernar son falsedades de palabras lícita, falsedades que se tornan útiles y terapéuticas. Aunque Platón no especifica en la República ningún ejemplo de noble mentira, sí manifiesta que es utilizada única y exclusivamente por los gobernantes.

La exposición sobre el buen gobernante que Platón propone en el Gorgias, como en otras obras (República), responde a la muerte de Sócrates, el gobernante ideal de la polis. Como puede observarse en la parte final 
de la obra, en pleno debate con Calicles y antes de acudir a la narración del "Mito sobre el juicio de los muertos y el destino final de las almas", Sócrates exhorta al sofista a que le indique a cuál de las dos formas de cuidar la ciudad lo invita: a luchar con energía para que los atenienses sean mejores, como haría un médico, o a servirlos y adularlos. Cuando Calicles responde que a servirlos y adularlos; Sócrates intuye qué le dirá Calicles y expresa lo siguiente:

¡No digas lo que has dicho tantas veces: "que me matará el que quiera”, para que yo tampoco te diga que "uno que es un malvado al que es bueno"! $\mathrm{Ni}$ tampoco que me robará, en caso de que tenga algo, para que no te responda yo tampoco: "pero, cuando me lo quite no sabrá qué hacer con ello, sino que, igual que me lo quitó injustamente, así también lo empleará injustamente". (Platón, Gorgias 521a-522a)

A continuación, y tras afirmar que sería un insensato si no creyese que en Atenas a cualquiera le puede pasar lo que sea, Sócrates apunta al centro de la cuestión al decir:

Creo que soy uno de los pocos atenienses (por no decir el único) que se dedica a la actividad verdaderamente política y que soy el único que en la actualidad se dedica a los asuntos públicos: como jamás digo nada por agradar, sino mirando en cada ocasión a lo que es mejor, no a lo que es más placentero, y como no quiero hacer esas vanidades que tú alabas, no sabré qué decir en un tribunal [...] y seré juzgado como un médico entre niños acusado por un cocinero. (Platón, Gorgias 521a-522a)

Sócrates anuncia su propia muerte en el Gorgias, una muerte que provoca la democracia ateniense y que acaba con la figura que representa al buen gobernante platónico de la polis. 


\section{La teoría política del Gorgias en el PRESENTE}

Tal y como hemos visto, la relación entre retórica y política está latente durante el desarrollo de la obra. Sin embargo, ateniéndonos a la opinión de los expertos sobre la sofística, son diversas las interpretaciones a tener en cuenta a la hora de vincular estos dos conceptos. De esta manera, Friedlander afirma que Gorgias tiene una gran seguridad en su retórica debido a la capacidad que posee para alcanzar el poder político (249); Irwin cree que la propuesta de Gorgias es un paso hacia la futura concepción de Estado en tanto que se propone un método para someter a los ciudadanos de la polis por su propio consentimiento y no mediante la fuerza física (117) y Jaeger, en su obra Paideia, analiza el diálogo desde un punto de vista netamente político (511).

En cualquier caso, pareciendo evidente que la relación entre retórica y política en el Gorgias es directa, el siguiente objeto a analizar es si la teoría política que destila la obra es adaptable a las ideas políticas del presente. $\mathrm{Al}$ respecto, nuestra tesis es que al tener la filosofía platónica y la sofística una estructura hilemórfica con normas, valores y racionalidad que incluyen conceptos, valores e ideas, estas últimas se mantienen, habiendo tenido un curso concreto el paso de las teorías políticas del pasado a las del presente. Además, no es solo la adaptación al presente de las ideas platónicas teóricamente hablando-, así se ha hecho de forma concreta en diferentes períodos históricos, especialmente, durante el siglo XX con las obras de Popper, Strauss o Arendt.

En el presente trabajo, a fuer de lo oportuno que resulta vincular la lectura política del Gorgias con el presente, se conectan dos fragmentos de la referida obra con dos ideologías reinantes en la actualidad. En primer lugar, la relación entre la diferencia de ciencia y creencia esbozada por Sócrates en el contexto del debate sobre la retórica y las ideologías derivadas de la posmodernidad. En segundo lugar, la idea de gobernante que manejan Calicles y Sócrates vinculadas con un tipo de movimiento populista surgido en la segunda década del siglo XXI. 
La ciencia contra la creencia y las ideologías de la posmodernidad

Como indicamos en el tercer apartado del presente artículo, en el debate que mantiene con Gorgias sobre la definición de retórica, Sócrates llega a la siguiente conclusión: como existe una creencia verdadera y una falsa, pero solo una ciencia verdadera, concurren dos clases de persuasión, una que proporciona la ciencia y otra que proporciona la creencia sin conocimiento. Lo relevante a efectos de la analogía que aquí tratamos es la división dicotómica entre ciencia y creencia a nivel político en virtud de sus orígenes, propios del ámbito del nous y de la doxa respectivamente. Recordemos que el orador -es decir, el político- hace una retórica que forma parte de la adulación en tanto que su fin es agradar y no buscar el bien de la polis; sin embargo, quien debe gobernar la ciudad es el que hace mejores a los ciudadanos, para lo que hace falta conocer el bien y, retornando a lo dicho, quien conoce bien es el filósofo, no el sofista o el filodoxo.

Pero, en este contexto queda dibujado el perfil del gobernante socrático como aquel que conoce el bien, cabe preguntarse lo siguiente: ¿cuál sería el fundamento filosófico de la sofística que reluce en el Gorgias? A este respecto, Zeller afirmó que la sofística es la causante de la negación de todas las leyes morales de validez universal como movimiento negador de la posibilidad del saber (39-94). Al criticar la tradición, perpetuó el actuar contingente del individuo, la arbitrariedad y la ventaja personal. Por esta razón se considera el pensamiento sofístico como simplista y anticientífico (Solana 97). Es, en resumidas cuentas, la base de la teoría que considera al sofista como un relativista y un escéptico moral. Si nos atenemos a este pensamiento y a lo expuesto en el Gorgias, es Calicles, el más político de los tres sofistas, quien practica este relativismo moral en su alegato defensor de la figura del tirano.

La política a la que se enfrenta Sócrates es la que está caracterizada por estos dos factores; a saber, aquella que se fundamenta en la creencia sin conocimiento y que gravita en torno al relativismo y al escepticismo moral. Si la pretensión es la analogía con el presente, hay que localizar la ideología política que siga estos patrones. Así, encontramos la primacía de la 
creencia sobre la ciencia en las ideologías derivadas de la posmodernidad y cristalizadas en las políticas de identidad. Si en un lado de la balanza, como advierte Platón en el Sofista, se encuentran las ciencias -y la filosofía- cuyos fundamentos son eliminar las opiniones y las informaciones que impiden el conocimiento; en el otro se encuentran las creencias, que se extienden con más fuerza que los conocimientos. (Platón, Sofista 230d)

En este sentido, la ideología política de la posmodernidad se articula bajo forma de mitos impulsando creencias dogmáticas e irracionales; en conceptos platónicos, se construyen en virtud de las imágenes, que son propias del ámbito de la doxa. Una de las razones por las que el posmodernismo se ha arraigado tan extensamente es que es mucho más fácil ser crítico que presentar una visión positiva. Aquí, en el epicentro de la dicotomía entre crítica e ideología es donde se percibe la analogía con ciencia y creencia platónica en virtud de las corrientes posmodernas, de las cuales surgieron, como consecuencia lógica, las políticas de identidad. La crítica que ha hecho Mark Lilla a estas continúa en esta misma línea: si la identidad se convierte en el argumento, al margen de cualquier otro, se constriñe el debate dentro de la esfera pública, erigiéndose el caldo de cultivo perfecto para la sentimentalización de la política. No en vano, asistimos a diario a un debate público caracterizado por la preeminencia de ideologías que se superponen a otras en virtud de criterios dogmáticos como su propia superioridad moral.

La denuncia de Platón a la política realizada desde la doxa y no desde el nous es equiparable al momento actual, representado por la traslación a la política de lo expuesto como el giro afectivo (the affective turn), donde la primacía de las emociones se integró en el terreno de las ciencias sociales y las humanidades a raíz del auge de las nuevas tecnologías. Esta llegada -o quizás deberíamos decir regreso- de la preponderancia emocional en la esfera pública es lo que Manuel Arias Maldonado ha denominado la democracia sentimental (2017), canalizada en fenómenos como la imposibilidad crítica a las políticas de identidad, el auge de los populismos, el empuje de nacionalismos de corte étnico y las campañas electorales que apelan a las emociones en pro de las razones. 
No obstante, la reflexión final de Sócrates en el Gorgias en la que proclama la necesidad de hacer una retórica en favor de la justicia nos exhorta a pensar que Platón hacía plausible un tipo de discurso que, fundamentado en el nous, no descuidara determinados elementos pasionales. En este sentido, nos recuerda a la reflexión que hace Martha Nussbaum sobre las emociones en el debate de la esfera pública del siglo XXI. Según la filósofa norteamericana, la defensa de estas es imprescindible para la consecución de la justicia. Como explica Arias Maldonado, para Nussbaum

el cultivo político de las emociones es necesario para lograr la adhesión ciudadana a aquellos proyectos que lo merecen. Se deduce de aquí que la frialdad del liberalismo terminaría siendo perjudicial para su propia realización práctica. (“La democracia sentimental” s.p.)

Se trataría de construir unas reglas del juego cimentadas en principios racionales, pero sin olvidar el papel de lo emocional. O en vocabulario platónico, que el discurso político se fundamente en el nous sin obviar la presencia de un tipo de persuasión; aquella que produce la ciencia (episteme).

Sophrosine contra pleonexia: del tirano de Calicles a Donald Trump

Aunque es, sin duda, en el diálogo con Calicles donde más se ahonda en el análisis sobre la figura del tirano y su comparación con el buen gobernante de la polis, Platón aborda esta cuestión con anterioridad en la conversación con Polo. Así, este afirma que el poder es un bien y que, en virtud de ello, los tiranos, al tener la potestad de condenar a muerte a quien deseen y despojar de sus bienes a quien les parezca, son los más poderosos de la polis; argumento que Sócrates refuta por medio del elenkhos negando que el tirano tenga realmente poder (Platón, Gorgias 466e-469e). Sin embargo, es el monólogo con el que entra en escena Calicles donde se perfila la figura del tirano que defienden los sofistas del Gorgias. En un contexto de primacía de la physis sobre el nomos, Calicles explica que quienes establecen las leyes son 
los débiles que forman la mayoría por temor a que los hombres que son más fuertes y poderosos tengan más; razón por la que, por ley, esto se entiende como injusto y vergonzoso. Es la naturaleza misma la que demuestra que es justo que el fuerte tenga más que el débil y el poderoso más que el que no lo es. Y concluye afirmando:

Pero en caso de que llegue a haber un hombre suficientemente dotado por la naturaleza, sacudiéndose de encima todas estas cosas, quebrándolas por medio y zafándose de ellas, pisoteando nuestros escritos, y trucos, y encantos y leyes todas que transgreden la naturaleza, alcanzándose en rebelión el esclavo, se revelaría como el señor y brillaría entonces la justicia de la naturaleza. (Platón, Gorgias 483b-484b)

Para el sofista, como afirma tras la contestación de Sócrates, lo bello y justo por naturaleza es que el hombre sacie con decisión lo que en cada ocasión sea objeto de deseo; pero al no ser esto posible para la mayor parte de la gente, censuran a los poderosos ocultando su propia impotencia (Platón, Gorgias 492a). Luego, Calicles defiende la ambición desmedida de poder del tirano, que para alcanzar lo bello y justo por naturaleza ha de satisfacer, en primer lugar, sus propios deseos y, como bien máximo, los de los ciudadanos de la polis. Este insaciable apetito es lo que los griegos dieron a llamar pleonexia.

Sócrates responde a Calicles, pero ante su abrupta interrupción comienza por recordarle que entre ellos dos existe una diferencia: uno ama a la filosofía y el otro al demos de Atenas. Mientras que el sofista sacrifica las palabras a las que ama si el pueblo así lo desea, Sócrates dice siempre lo mismo (Platón, Gorgias 481d). De nuevo, Platón enfrenta las dos figuras, la del filósofo y la del filodoxo. Una vez expuesta la teoría de Calicles sobre la satisfacción del placer como virtud, Sócrates responde rededuciendo que ni el poderoso es el más fuerte ni lo placentero y lo bueno son la misma cosa. Si el buen gobernante, a diferencia del orador, es el que satisface aquellos deseos cuyo cumplimiento mejoran al hombre y no los que, satisfecho, lo empeoran y si, a su vez, el alma con orden y armonía, tanto del hombre 
como de la polis, es buena y la contrario mala; entonces, el gobernante ha de aspirar a la moderación (sophrosine). Frente al alegato a la desinhibición que realiza Calicles con la pleonexia como telón de fondo, el filósofo responde con la búsqueda de la justicia (dikaiosyne) y la moderación (sophrosine). Y concluye Sócrates exhortando al sofista a que le responda a la siguiente pregunta; si este es el perfil del buen gobernante, ¿ha hecho ya Calicles mejor a algún ciudadano? Y si esto es lo que un hombre bueno debe procurar a la polis, ¿sigue afirmando Calicles que Pericles, Cimón, Milcíades y Temístocles fueron buenos ciudadanos? Sócrates remata afirmando que, al corromperse saciando los deseos de los ciudadanos de la polis sin tener moderación, estos políticos se consolidaron como malos administradores de la ciudad (Platón, Gorgias 515a-519b). Como ya anunciamos, Platón denuncia la corrupción del sistema: solo alguien como Sócrates puede gobernar la polis; pero ante las acusaciones ajenas y en tanto filósofo y no orador, no podrá defenderse ante los tribunales. Su final está escrito.

Pero, ateniéndonos a lo que en este punto analizamos, ¿̨cuál sería la adaptación política al presente de las ideas de Sócrates y especialmente de Calicles sobre el gobernante ideal? Recordemos, para el sofista lo justo por naturaleza es que el poderoso sea más que quien no lo es y que el bien para los ciudadanos sea la satisfacción de sus propios deseos; mientras que para el filósofo debe administrar la polis y, proponiendo el orden del alma de esta y en pos de la moderación y la justicia, tener como fin mejorar a los ciudadanos. Una primera observación al panorama político de hoy en relación con el vínculo existente entre el gobernante y los ciudadanos nos lleva irremediablemente hacia una analogía con el populismo. Pero, ¿cuál es la relación de lo expuesto por Calicles y el tipo de populismo al que hacemos referencia en este apartado? Para encontrar esta vinculación, es preciso que en primer lugar definamos populismo, labor compleja puesto que el término ha sido utilizado en contextos diferentes con significados diferentes. Tal y como señalan Máriam Martínez-Bascuñán y Fernando Vallespín, si todo es populismo, nada lo es (38 y ss.). Así, Cas Mudde lo define como la ideología que observa en la sociedad una división fundamental entre dos grupos homogéneos y antagónicos -los puros y la élite corrupta-, 
y que postula que la política debe expresar la voluntad general del pueblo (s.p.), añadiendo Martínez-Bascuñán y Vallespín y que los que pertenecen al grupo elegido recurren a la emocionalidad y a la simplificación (38 y ss.). Arias Maldonado completa esta definición haciendo referencia a que, si la aparición de esta ideología debe entenderse como una respuesta al desorden por la acelerada marcha de las sociedades modernas y al desvanecimiento de las estructuras políticas reinantes en el siglo XXI, entonces la respuesta es la aparición de la nostalgia por un soberano capaz de poner orden en el caos, siendo este el tipo de populismo que aquí comparamos ("El enigma”).

En este sentido, encontramos tres similitudes entre los elementos que conforman la definición de populismo y lo expuesto por Platón en el Gorgias. Primero, el grupo puro definido por Mudde responde a la voluntad general del pueblo, por lo que saciará los deseos de los ciudadanos de la polis. Segundo, y siguiendo a Martínez-Bascunán y Vallespín, como aquellos que pertenecen al grupo elegido tienden a la apelación política de los sentimientos, articulan su discurso en virtud de la doxa y no del nous, al igual que ocurría en el caso de las ideologías de la posmodernidad. No en vano, posmodernismo y populismo son conceptos estrechamente vinculados. Tercero, la aspiración a la aparición de un soberano que ordene el caos es similar al anhelo de Calicles por la venida del tirano que, debido a la virtud de su poder y por justicia natural (physis), imponga su fuerza. Contra estas tres características, Sócrates presenta al gobernante filósofo que solo satisfaga aquellos deseos cuyo cumplimiento mejoran al ciudadano y cuyo discurso, aun pudiendo apelar a ciertas emociones, se construya en virtud del nous y no de la doxa.

\section{Conclusión}

Platón aborda en el Gorgias un análisis sobre la retórica, que resulta una práctica y no un arte en tanto que, formando parte de la adulación, finge ser una tekhnai para, por medio de lo agradable, producir engańo con el fin de alcanzar lo placentero sin el bien. Este tipo de retórica se enfrenta a 
la filosofía por estar articulada en virtud de la doxa (opinión) y no del nous (razón), siendo esta dicotomía clave para entender el pensamiento platónico puesto que este se construye contra los sofistas y oradores. Sin embargo, la retórica descrita no es la única realmente existente para Platón. La clave de esta afirmación la encontramos en la parte final del Gorgias, cuando Sócrates manifiesta que esta ha de usarse siempre en favor de la justicia. La retórica aquí referida es aquella que origina la ciencia en contraposición a la que produce la creencia sin el conocimiento.

Luego, la figura que ha de servirse de la retórica y de otras acciones en pos de la búsqueda de la justicia será el buen gobernante, encargado de gobernar la polis. Para ello, deberá conocer porque sin conocimiento (episteme) no hay excelencia (arete); siendo la razón de esto impedir que los ignorantes gobiernen. Estos ignorantes son los que buscan lo mejor para sí; a saber, los tiranos. En conclusión, quien debe administrar la ciudad no será el filodoxo sino el filósofo.

Esta construcción teórica nos lleva a considerar al Gorgias como una obra con un amplio fundamento político adaptable a los parámetros de hoy. De esta manera, encontramos dos grandes ideologías del presente vinculadas con lo expuesto por Platón en el diálogo que aquí tratamos: el posmodernismo y el populismo. Con respecto a la primera de ellas, su vínculo con la sofística es que ambas se estructuran en forma de mitos a fuer de impulsar creencias dogmáticas e irracionales; lo que en conceptos platónicos significa que se construyen en virtud de las imágenes que son propias del ámbito de la doxa. La consecuencia de este relativismo dogmático es la sentimentalización de la política, canalizada en diversos fenómenos. Contra esto, Platón esgrime el gobierno de los filósofos, que, aunque se sirvan de un tipo de retórica (la que proporciona la ciencia), se fundamentan en el ámbito del nous. Asimismo, definiendo el populismo como la ideología que observa en la sociedad una división en dos grupos homogéneos y antagónicos -los puros y la élite corrupta- y que postula que la política debe expresar la voluntad general del pueblo recurriendo a la emocionalidad y ańorando la aparición de un soberano capaz ordenar el caos, la analogía con el Gorgias la encontramos en la figura del tirano descrita 
por Calicles, que coincide en tres aspectos con la definición de populismo: la tendencia del tirano por saciar los deseos de los ciudadanos de la polis a responder a la voluntad general del pueblo, la predisposición a la apelación emocional en política en tanto miembros de un grupo moralmente superior y la aspiración a la aparición de un tirano que, debido a la virtud de su poder y por justicia natural, ordene el caos. Contra estas tres características, Platón construye su concepto de gobernante ideal, representado por Sócrates. Es el filósofo que solo satisfaga aquellos deseos cuyo cumplimiento mejoran al ciudadano y cuyo discurso, aun pudiendo apelar a ciertas emociones, se construye en virtud del nous y no de la doxa. Es decir, aquel que busque el bien del alma de la polis. 


\section{Bibliografía}

Arias Maldonado, Manuel. "La democracia sentimental". Letras Libres, 21 junio 2014, www.letraslibres.com/mexico-espana/la-democracia-sentimental.

_. La democracia sentimental: política y emociones en el siglo XXI. Barcelona: Página Indómita, 2017.

_. "El enigma populista”. El Mundo, 9 enero 2019. www.elmundo.es/ opinion/2019/01/09/5c34b22821 efa0fb078b45f3.html.

Bueno, Gustavo. "Análisis del Protágoras de Platón". Filosofía.org, 1980 www. filosofia.org/cla/pla/1980gbpr.htm

Castoriadis, Cornelius. Lo que hace a Grecia: de Homero a Heráclito: Buenos Aires, FCE, 2006.

Friedlander, Paul. Plato: The Dialogues: First Period. Nueva York: Bollingen Foundation, 1964.

Guthrie, William Keith Chambers. Historia de la filosofia griega: Siglo V: Ilustración/ Versión española de Joaquín Rodríguez Feo. Madrid: Gredos, 1988.

Irwin, Terence. Gorgias. Nueva York: Oxford UP, 1979

Jaeger, Werner Wilhem. Paideia: los ideales de la cultura griega. México D. F.: FCE, 2001.

Lilla, Mark. El regreso liberal. Más allá de la política de la identidad. Barcelona: Debate, 2018.

Martínez-Bascunán, Máriam y Fernando Vallespín. Populismo. Madrid: Alianza, 2017.

Melero, Antonio. Sofistas: testimonios y fragmentos. Madrid: Gredos, 1996.

Mudde, Cas. "De qué se nutre el populismo". El Pais, 19 de abril de 2017, www. elpais.com/elpais/2017/03/29/opinion/1490788864_063591.html.

Platón. Diálogos I. Apología; Critón; Eutifrón; Ion; Lisis; Cármides; Hipias menor; Hipias mayor; Laques; Protágoras. Madrid: Gredos, 1981-1985.

_. Gorgias. Madrid: Consejo Superior de Investigaciones Científicas de Madrid, 2000.

_. República. Madrid: Alianza, 2013. 
Sánchez Tarifa, José Antonio. "Retórica, ética y política en Gorgias y Fedro". Contrastes. Revista Interdisciplinar de Filosofia, vol. II, 1997, pp. 292-313.

Solana, José. "Sofistas". Historia de la filosofía antigua, vol. 14, 1997, pp. 89-112.

Tonti, Silvia L. "La crítica del Gorgias a la retórica sofística y su relación con la primera definición de sofista en el diálogo homónimo". Revista Synthesis, n. ${ }^{\circ}$ 6, 1999, pp. 115-35.

Zeller, Eduard. Sócrates y los sofistas. Buenos Aires: Nova, 1955. 